\title{
Examining healthcare professionals' beliefs and actions regarding the physical health of people with schizophrenia
}

\author{
Alexandra Berry ${ }^{1^{*}}$ (D), Richard J. Drake ${ }^{1,2}$ and Alison R. Yung ${ }^{1,3}$
}

\begin{abstract}
Background: People with schizophrenia have a higher premature mortality risk compared with the general population mainly due to cardiovascular disease (CVD). Despite this, people with schizophrenia are less likely to access physical health services or have their physical health investigated and monitored.

Aims: To examine the beliefs and actions of mental health professionals regarding the physical health of people with schizophrenia.

Method: Two hundred and fifty-five healthcare professionals who support people with schizophrenia within Greater Manchester Mental Health NHS Foundation Trust (GMMH), United Kingdom and Pennine Care NHS Foundation Trust (PCFT), United Kingdom took part. Beliefs and actions were assessed using a self-administered questionnaire, which was constructed around two primary domains (1) CVD risk factors; and (2) physical health interventions. Descriptive statistics were reported and responses between different healthcare professional groups were compared.
\end{abstract}

Results: The overwhelming majority of participants were aware of established CVD risk factors with 98\% identifying family history of CVD, 98\% for smoking and 96\% for high blood pressure. Most participants believed nearly all healthcare professionals were responsible for monitoring the physical health of people with schizophrenia, regardless of job speciality. There were $67 \%$ of participants who reported delivering an intervention to improve sedentary behaviour for people with schizophrenia. However, awareness of government and NHS recommended lifestyle interventions were low.

Conclusions: This study found good knowledge regarding many established CVD risk factors but little clarity regarding who is responsible for monitoring the physical health of people with schizophrenia and how often brief lifestyle interventions are being implemented.

Keywords: Health professional, Cardiovascular, Risk factors, Lifestyle, Professional practice

\footnotetext{
* Correspondence: alexandra.berry-2@postgrad.manchester.ac.uk

'Division of Psychology \& Mental Health, School of Health Sciences, Faculty

of Biology, Medicine and Health, University of Manchester, Manchester

Academic Health Sciences Centre (MAHSC), Manchester, UK

Full list of author information is available at the end of the article
}

(C) The Author(s). 2020 Open Access This article is licensed under a Creative Commons Attribution 4.0 International License, which permits use, sharing, adaptation, distribution and reproduction in any medium or format, as long as you give appropriate credit to the original author(s) and the source, provide a link to the Creative Commons licence, and indicate if changes were made. The images or other third party material in this article are included in the article's Creative Commons licence, unless indicated otherwise in a credit line to the material. If material is not included in the article's Creative Commons licence and your intended use is not permitted by statutory regulation or exceeds the permitted use, you will need to obtain permission directly from the copyright holder. To view a copy of this licence, visit http://creativecommons.org/licenses/by/4.0/ The Creative Commons Public Domain Dedication waiver (http://creativecommons.org/publicdomain/zero/1.0/) applies to the data made available in this article, unless otherwise stated in a credit line to the data. 


\section{Introduction}

People with schizophrenia have a reduced life expectancy by one to two decades and a premature mortality risk two to three times higher than the general population [1-3]. The most common cause of death in this group is cardiovascular disease (CVD) [4-6], with a more than double risk of death from CVD compared with the general population, according to a large-scale meta-analysis [7]. Physical health comorbidity is one cause of the poor health outcomes seen in this group, who have been shown to have high prevalence of obesity [8], type 2 diabetes [9], dyslipidaemia and hypertension [10]. Antipsychotic medication, prescribed to manage symptoms, can cause adverse side effects of metabolic syndrome [11] (defined as central obesity, plus any two of raised triglycerides, reduced highdensity lipoprotein-cholesterol, raised blood pressure, raised fasting plasma glucose [12]). However, as increased risk of cardiometabolic diseases in people with schizophrenia can arise even prior to antipsychotic treatment [13], unhealthy lifestyle factors may also play a part, including increased prevalence of smoking [14], sedentary behaviour [15] and dysregulated sleep patterns $[16,17]$.

An added problem is that people with schizophrenia are less likely than people in the general population to report physical health problems [18-20], access health services for physical health concerns [21] and have these issues investigated and monitored [22, 23]. Lack of clarity about who is responsible for the physical health of mental health service users may contribute to this problem [24]. While primary care staff likely have the necessary skills and expertise to perform physical health assessments, knowledge and confidence may be lacking in relation to supporting people with schizophrenia [25]. A survey found $47.2 \%$ of practice nurses administer antipsychotic injections, yet only $9.4 \%$ monitor for side effects using a validated rating scale [26]. This can lead to 'diagnostic overshadowing' whereby treating healthcare professionals could attribute physical symptoms to an existing mental health diagnosis and subsequently do not investigate [27].

The aim of this study is therefore to examine the beliefs and actions of healthcare professionals who support people with schizophrenia, in relation to their patients' physical health.

\section{Method \\ Sample}

We surveyed healthcare professionals who were currently working in a job role that involved contact with one or more individuals with a diagnosis of schizophrenia or related psychosis, according to the ICD-10 classification system [28]. Participants were recruited from Greater Manchester Mental Health NHS Foundation Trust (GMMH), United Kingdom (UK) and Pennine Care NHS Foundation Trust (PCFT), UK. Participants with a clinical role in supporting people with schizophrenia were identified and contacted by National Institute for Health Research (NIHR) Clinical Research Network (CRN) clinical studies officers (CSOs). The study received ethical approval from the North West Research Ethics Committee (17/NW/0368). It was also adopted by the NIHR CRN Portfolio (34859). There were 255 participants included in this study, 119 were recruited from GMMH and 136 were recruited from PCFT.

\section{Questionnaire development}

The self-administered questionnaire was constructed around two primary domains [1] CVD risk factors; and [2] physical health interventions (Supplementary materials). The first section of the questionnaire asked about gender, job specialty, area of work, time worked in the profession and NHS trust. The second section asked participants to select on a checklist: "Which of the following do you think are risk factors for cardiovascular disease? Please tick all that apply". Risk factors were included based on published literature $[29,30]$ and UK national clinical guidelines to improve health and social care by the National Institute for Health and Care Excellence (NICE) [31, 32]. Additional misleading variables, i.e. hair dye and mobile phone use, were also included as options to determine if any participants simply checked all items. Participants were excluded from the analyses if all misleading items were checked. For the purpose of this study, we considered risk factors to be established predictors of CVD if they were stated as such in NICE publications [31, 32] or used in algorithms for CVD risk prediction scores that could be applied to people with schizophrenia [33, 34].

The third section asked participants questions relating to physical health monitoring and interventions. First, participants were asked to select on a checklist which healthcare professionals they felt were responsible for monitoring the physical health of people with schizophrenia. Second, participants were asked a dichotomous question: "Have you ever delivered any effective interventions to improve sedentary behaviour in people with schizophrenia?" If participants answered "yes" they were then asked an open-ended question with a section to write comments: "If you answered yes, please specify the intervention(s)". Finally, participants were asked dichotomous questions on whether they had heard of government recommended lifestyle interventions; Making Every Contact Count (MECC), which is an NHS approach for healthcare professionals to support lifestyle related behaviour change in any patient they come into contact with [35]; and Very Brief Advice (VBA) on smoking, which involves short and simple advice that healthcare professionals can provide opportunistically, with any patient they come into contact with who 
smokes [36]. An additional misleading (i.e. non-existent) intervention 'VBA on sedentary behaviour' was also included. If participants selected "yes" to having heard of any of these interventions, they were then asked if they had ever delivered the intervention to someone with schizophrenia.

\section{Questionnaire distribution}

A cross-sectional online survey was distributed to participants within community mental health teams and inpatient settings using SelectSurvey.net (v4.146.001; ClassApps, Overland Park, KS, U.S.A.). Additionally, the survey was available in paper format for participants to complete and post back to the research team if they preferred. Preferred method of survey delivery was ascertained by the recruiting CSOs. All individual responses were checked for each completed survey by a researcher to ensure participants did not submit duplications via SelectSurvey.net and paper format. Participants received an information sheet to read, via SelectSurvey.net or as an attachment with the paper version. As no identifiable information was requested from participants, anonymity was preserved.

\section{Statistical analyses}

After recruitment was completed, the survey was closed and data were downloaded from the SelectSurvey.net website and imported into Microsoft Excel software. Data were then analysed using STATA (version 13; Statacorp, TX, USA). Descriptive statistics were reported as percentages. Depending on their job role, healthcare professionals were grouped as follows: Non-qualified clinical staff, nurses, senior/managerial clinical staff, allied health professionals and medical practitioners. Specifically, the non-qualified clinical staff group comprised healthcare assistants/support workers, assistant psychologists, occupational therapy assistants, recovery/service user co-ordinators and student nurses. The nurses group comprised of mental health nurses (hospital), community psychiatric nurses, clozapine nurses and research nurses. The allied health professionals group comprised psychologists, cognitive behavioural therapy (CBT) therapists, occupational therapists, social workers, pharmacists and dietitians. The medical practitioners group comprised consultant psychiatrists, junior doctors and specialty doctors. A comparison between grouped healthcare professionals and all survey responses was made using Chi-square test, or where the expected cell count was below 5, a Fisher's exact test. Differences between the groups were considered statistically significant if the $p$-value was less than 0.05 .

\section{Results}

Summary data

In total 255 participants completed the survey between May 2018 and September 2018, of whom 69\% were female and $41.9 \%$ were nurses. Summary data for participant characteristics can be seen in Table 1.

\section{Risk factors for CVD}

Almost all participants identified family history of CVD (98\%), smoking (98\%) and high blood pressure (96\%) as risk factors for CVD. About three-quarters of participants identified age and antipsychotic/antidepressant medication as a risk factor. Diabetes was identified as a risk factor for CVD by $72 \%$, ethnicity by $55 \%$ and sleep problems by $45 \%$ of participants. Table 2 shows the findings from the full list of risk factors that were available for participants to select. Among the risk factors presented, Chi-square analyses revealed significant differences between healthcare professional groups (non-qualified clinical staff, nurses, senior/managerial clinical staff, allied health professionals and medical practitioners) in whether they believed that ethnicity, diabetes and antipsychotic/antidepressant medication are risk factors for CVD (Table 3). Compared with other groups, non-qualified

Table 1 Characteristics of healthcare professionals $(N=255)$

\begin{tabular}{|c|c|c|}
\hline & Number & Percent \\
\hline \multicolumn{3}{|l|}{ NHS Trust } \\
\hline GMMH & 119 & 46.7 \\
\hline PCFT & 136 & 53.3 \\
\hline \multicolumn{3}{|l|}{ Gender } \\
\hline Male & 73 & 28.7 \\
\hline Female & 176 & 69.3 \\
\hline \multicolumn{3}{|l|}{ Time in profession } \\
\hline Less than 1 year & 15 & 5.9 \\
\hline $1-4$ years, 11 months & 60 & 23.7 \\
\hline $5-9$ years, 11 months & 50 & 19.8 \\
\hline 10-19 years, 11 months & 72 & 28.5 \\
\hline More than 20 years & 56 & 22.1 \\
\hline \multicolumn{3}{|l|}{ Job role } \\
\hline Non-qualified clinical staff & 69 & 27.3 \\
\hline Nurses & 106 & 41.9 \\
\hline Senior/managerial clinical staff & 14 & 5.5 \\
\hline Allied health professionals & 42 & 16.6 \\
\hline Medical practitioners & 22 & 8.7 \\
\hline \multicolumn{3}{|l|}{ Workplace } \\
\hline Inpatient care & 115 & 45.3 \\
\hline Community mental health team & 68 & 26.8 \\
\hline Early intervention in psychosis & 30 & 11.8 \\
\hline Rehabilitation & 15 & 5.9 \\
\hline Substance misuse services & 4 & 1.6 \\
\hline Crisis resolution & 6 & 2.4 \\
\hline A day unit & 4 & 1.6 \\
\hline Other community services & 12 & 4.7 \\
\hline
\end{tabular}


Table 2 Summary of risk factors identified by professional groups for CVD ( $N=255)$

\begin{tabular}{|c|c|c|c|c|c|c|}
\hline Risk factors & $\begin{array}{l}\text { Non-qualified clinical } \\
\text { staff } \\
\text { N (\%) }\end{array}$ & $\begin{array}{l}\text { Nurses } \\
N(\%)\end{array}$ & $\begin{array}{l}\text { Senior/managerial clinical } \\
\text { staff } \\
\text { N (\%) }\end{array}$ & $\begin{array}{l}\text { Allied health } \\
\text { professionals } \\
\mathrm{N}(\%)\end{array}$ & $\begin{array}{l}\text { Medical } \\
\text { practitioners } \\
\text { N (\%) }\end{array}$ & $\begin{array}{l}\text { Total } \\
\text { N (\%) }\end{array}$ \\
\hline $\mathrm{ab}_{\text {Family history of CVD }}$ & $68(98.6)$ & $\begin{array}{l}103 \\
(97.2)\end{array}$ & $13(92.9)$ & $42(100)$ & $22(100)$ & $\begin{array}{l}250 \\
(98.0)\end{array}$ \\
\hline${ }^{\mathrm{ab}}$ Smoking & $66(95.7)$ & $\begin{array}{l}104 \\
(98.1)\end{array}$ & $14(100)$ & $41(97.6)$ & $22(100)$ & $\begin{array}{l}249 \\
(97.7)\end{array}$ \\
\hline${ }^{a b}$ High blood pressure & $64(92.8)$ & $\begin{array}{l}103 \\
(97.2)\end{array}$ & $14(100)$ & $40(95.2)$ & $22(100)$ & $\begin{array}{l}245 \\
(96.1)\end{array}$ \\
\hline ab Obesity & $63(91.3)$ & $\begin{array}{l}102 \\
(96.2)\end{array}$ & $11(78.6)$ & $40(95.2)$ & $22(100)$ & $\begin{array}{l}240 \\
(94.1)\end{array}$ \\
\hline${ }^{\mathrm{ab}}$ High cholesterol & $63(91.3)$ & $\begin{array}{l}97 \\
(91.5)\end{array}$ & $14(100)$ & $41(97.6)$ & $22(100)$ & $\begin{array}{l}239 \\
(93.7)\end{array}$ \\
\hline aLack of physical activity & $64(92.8)$ & $\begin{array}{l}96 \\
(90.1)\end{array}$ & $14(100)$ & $39(92.9)$ & $21(95.5)$ & $\begin{array}{l}236 \\
(92.6)\end{array}$ \\
\hline${ }^{\mathrm{b}}$ Alcohol consumption & $60(87.0)$ & $\begin{array}{l}93 \\
(87.7)\end{array}$ & $11(78.6)$ & $32(76.2)$ & $18(81.8)$ & $\begin{array}{l}216 \\
(84.7)\end{array}$ \\
\hline${ }^{\mathrm{C}}$ Poor diet & $54(78.3)$ & $\begin{array}{l}93 \\
(87.7)\end{array}$ & $12(85.7)$ & $32(76.2)$ & $20(90.9)$ & $\begin{array}{l}212 \\
(83.1)\end{array}$ \\
\hline 'Substance abuse & $58(84.1)$ & $\begin{array}{l}87 \\
(82.1)\end{array}$ & $11(78.6)$ & $33(78.6)$ & $16(72.3)$ & $\begin{array}{l}206 \\
(80.8)\end{array}$ \\
\hline${ }^{\mathrm{ab}}$ Age & $49(71.0)$ & $\begin{array}{l}84 \\
(79.3)\end{array}$ & $10(71.4)$ & $30(71.4)$ & $18(81.8)$ & $\begin{array}{l}193 \\
(75.7)\end{array}$ \\
\hline $\begin{array}{l}{ }^{\mathrm{ab}} \text { Antipsychotic/antidepressant } \\
\text { medication }\end{array}$ & $42(60.9)$ & $\begin{array}{l}83 \\
(78.3)\end{array}$ & $10(71.4)$ & $32(76.2)$ & $20(90.9)$ & $\begin{array}{l}189 \\
(74.1)\end{array}$ \\
\hline${ }^{\mathrm{ab}}$ Diagnosis of type 2 diabetes & $42(60.9)$ & $\begin{array}{l}75 \\
(70.8)\end{array}$ & $10(71.4)$ & $34(81.0)$ & $20(90.9)$ & $\begin{array}{l}183 \\
(71.8)\end{array}$ \\
\hline Other psychiatric medication & $32(46.4)$ & $\begin{array}{l}70 \\
(66.0)\end{array}$ & $10(71.4)$ & $24(57.1)$ & $12(54.6)$ & $\begin{array}{l}150 \\
(58.8)\end{array}$ \\
\hline${ }^{\mathrm{ab}}$ Ethnicity & $22(31.9)$ & $\begin{array}{l}64 \\
(60.4)\end{array}$ & $8(57.1)$ & $26(61.9)$ & $17(77.3)$ & $\begin{array}{l}139 \\
(54.5)\end{array}$ \\
\hline Red meat consumption & $36(52.2)$ & $\begin{array}{l}49 \\
(46.2)\end{array}$ & $7(50.0)$ & $23(54.8)$ & $11(50.0)$ & $\begin{array}{l}128 \\
(50.2)\end{array}$ \\
\hline Caffeine consumption & $34(49.3)$ & $\begin{array}{l}51 \\
(48.1)\end{array}$ & $8(57.1)$ & $23(54.8)$ & $5(22.7)$ & $\begin{array}{l}122 \\
(47.8)\end{array}$ \\
\hline${ }^{\mathrm{C}}$ Poor sleep & $33(47.8)$ & $\begin{array}{l}44 \\
(41.5)\end{array}$ & $5(35.7)$ & $19(45.2)$ & $12(54.6)$ & $\begin{array}{l}114 \\
(44.7)\end{array}$ \\
\hline Dehydration & $25(36.2)$ & $\begin{array}{l}34 \\
(32.1)\end{array}$ & $6(42.9)$ & $17(40.5)$ & $3(13.6)$ & $\begin{array}{l}86 \\
(33.7)\end{array}$ \\
\hline Lack of access to green spaces & $19(27.5)$ & $\begin{array}{l}30 \\
(28.3)\end{array}$ & $2(14.3)$ & $12(28.6)$ & $7(31.8)$ & $\begin{array}{l}71 \\
(27.8)\end{array}$ \\
\hline${ }^{c}$ Air pollution & $19(27.5)$ & $\begin{array}{l}22 \\
(22.6)\end{array}$ & $3(21.4)$ & $13(31.0)$ & $3(13.6)$ & $\begin{array}{l}63 \\
(24.7)\end{array}$ \\
\hline Noise pollution & $5(7.3)$ & $10(9.4)$ & $1(7.1)$ & $6(14.3)$ & $1(4.6)$ & $23(9.0)$ \\
\hline Vaccinations & $5(7.3)$ & $4(3.8)$ & 0 & $1(2.4)$ & $1(4.6)$ & $11(4.3)$ \\
\hline Hair dye & $3(4.4)$ & $3(2.8)$ & 0 & 0 & 0 & $6(2.4)$ \\
\hline Mobile phone use & $2(2.9)$ & $3(2.8)$ & 0 & $1(2.4)$ & 0 & $6(2.4)$ \\
\hline
\end{tabular}

${ }^{\mathrm{a}}$ Established risk factors according to NICE; ${ }^{\mathrm{b}}$ Established risk factors according to CVD risk prediction scores applicable to people with schizophrenia [33, 34]; ${ }^{\mathrm{C}}$ Not an established CVD risk factor according to NICE, but there is some evidence for it increasing CVD risk in published literature

clinical staff were significantly less likely to identify ethnicity (31.9\% vs range: $57.1-77.3 \%, \chi^{2}=21.24 ; p<0.001$ ), diabetes (60.9\% vs range: $\left.70.8-90.9 \%, \chi^{2}=9.77 ; p=0.04\right)$ and antipsychotic/antidepressant medication (60.9\% vs range: $71.4-$ 90.9\%; $\chi^{2}=10.60 ; p=0.03$ ) as CVD risk factors (Table 3).

\section{Physical health monitoring} Responsibility

Similar numbers of participants believed the responsibility to monitor the physical health of schizophrenia was that of general practitioners (GPs) (93\%), mental health 
Table 3 Comparison between groups on beliefs of risk factors for CVD

\begin{tabular}{|c|c|c|c|c|c|c|}
\hline & \multicolumn{2}{|c|}{ Ethnicity } & \multicolumn{2}{|c|}{ Diabetes } & \multicolumn{2}{|c|}{ Antipsychotic/antidepressant medication } \\
\hline & $\mathrm{N}$ & $\%$ & $\mathrm{~N}$ & $\%$ & $\mathrm{~N}$ & $\%$ \\
\hline Non-qualified clinical staff & 22 & 31.9 & 42 & 60.9 & 42 & 60.9 \\
\hline Nurses & 64 & 60.4 & 75 & 70.8 & 83 & 78.3 \\
\hline Senior/managerial clinical staff & 8 & 57.1 & 10 & 71.4 & 10 & 71.4 \\
\hline Allied health professionals & 26 & 61.9 & 34 & 81.0 & 32 & 76.2 \\
\hline Medical practitioners & 17 & 77.3 & 20 & 90.9 & 20 & 90.9 \\
\hline$x^{2}$ & \multicolumn{2}{|c|}{21.239} & \multicolumn{2}{|c|}{${ }^{\mathrm{a}} 9.772$} & \multicolumn{2}{|l|}{${ }^{\mathrm{a}} 10.601$} \\
\hline$P$ & \multicolumn{2}{|c|}{$<0.001$} & \multicolumn{2}{|c|}{0.04} & \multicolumn{2}{|l|}{0.03} \\
\hline
\end{tabular}

${ }^{\mathrm{a}}$ Fisher's exact was used due to some cell counts being $<5$

nurses (hospital) (93\%), consultant psychiatrists (93\%), community psychiatric nurses (92\%) and GP nurses (91\%) (Fig. 1). There was no significant difference between groups regarding perceptions of who had responsibility for physical healthcare.

\section{Interventions}

In total $67 \%$ of participants said at some point they had delivered an effective intervention to improve sedentary behaviour in people with schizophrenia and groups differed significantly $\left(x^{2}=28.67 ; p<0.001\right)$. The group with the highest proportion of participants to answer yes to this question was nurses $(83.5 \%, n=86,34 \%$ of the total). The most common intervention across all groups was signposting, i.e. directing patients to services or sources of advice (38\%, $n=64,25 \%$ of the total) (Fig. 2).

In regards to government recommended interventions, $28 \%(n=70)$ of participants had heard of MECC, of whom $42 \%(n=26,10 \%$ of the total $)$ stated they had used this intervention with someone with schizophrenia. $38 \%(n=97)$ of participants had heard of Very Brief Advice (VBA) on smoking, of whom $60 \%(n=56,22 \%$ of the total) stated they had delivered this intervention to someone with schizophrenia. $13 \%$ of participants $(n=$

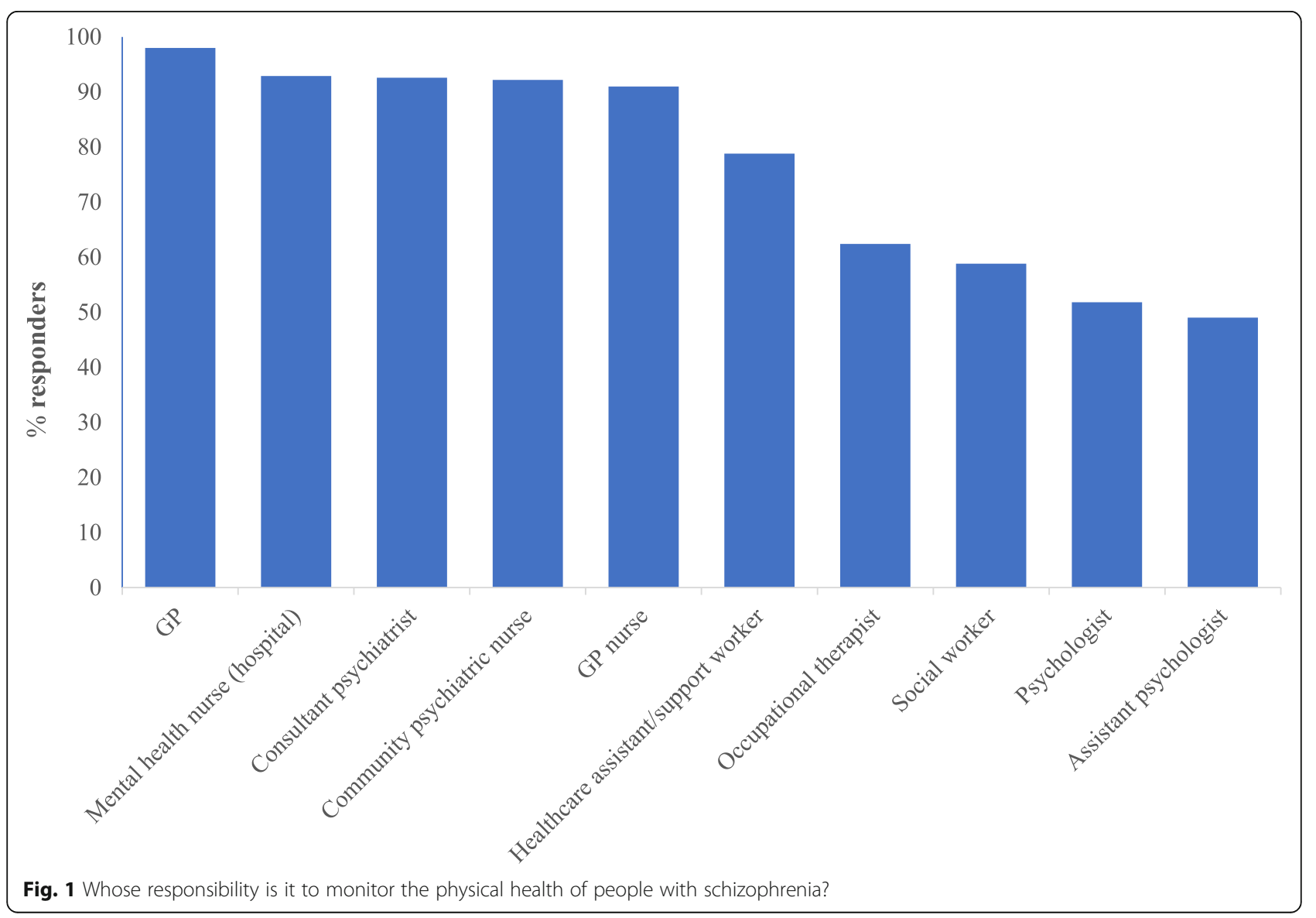




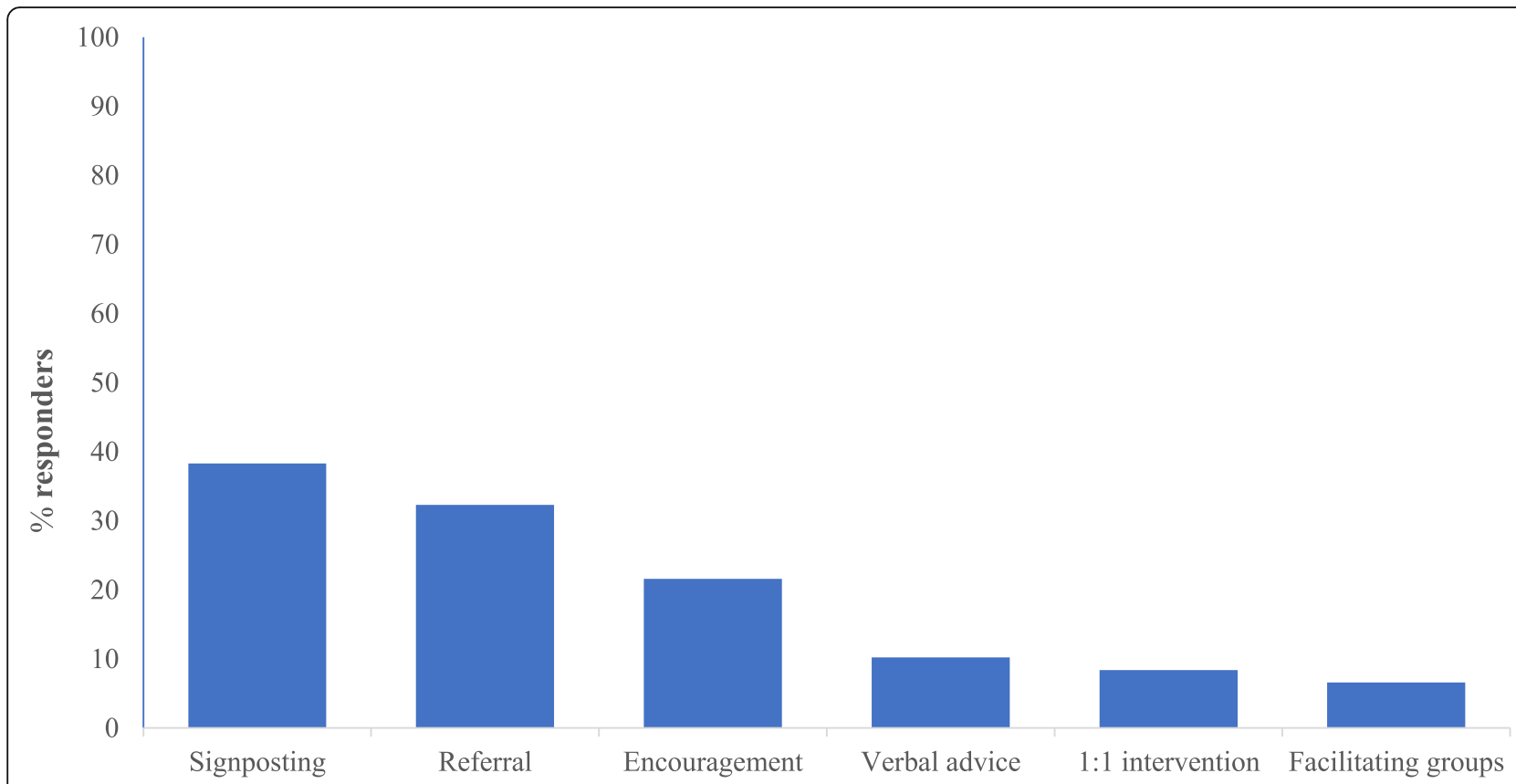

Fig. 2 Interventions for improving sedentary behaviour in people with schizophrenia

33) believed they had heard of a non-existent intervention, VBA on sedentary behaviour, of whom $68 \%(n=21$, $8 \%$ of the total sample) stated they had delivered this intervention to someone with schizophrenia. There was no significant difference between groups in whether they had heard of MECC, VBA on smoking or the nonexistent intervention VBA on sedentary behaviour. Nor did groups differ in whether they had delivered these interventions to someone with schizophrenia.

\section{Discussion}

Knowledge of many established risk factors for CVD was high, including some risk factors of particular relevance to schizophrenia patients, such as smoking, obesity and lack of physical activity. Other established risk factors of age, diabetes and ethnicity were less widely known. There was an educational gradient in recognition of diabetes, ethnicity and antipsychotic/antidepressant medication as risk factors, with more highly qualified professionals more likely to correctly identify these risk factors. Almost $75 \%$ of participants identified antipsychotic/antidepressant medication as a risk factor for CVD. Of concern was that nearly $10 \%$ of medical practitioners and over $20 \%$ of nurses were unaware that antipsychotic/antidepressant medication are risk factors for CVD. Antipsychotic use is stated to increase CVD risk in NICE guidance [32]. Antidepressant use was found to be associated with increased risk of CVD, independent of traditional risk factors in a CVD risk prediction model for people with severe mental illness (SMI) [34]. As well as cardiovascular side effects, antipsychotic treatment is associated with metabolic syndrome [11]. These side effects can lead to non-adherence [37], which is associated with increased use of healthcare resources [38] and reduced quality of life [39]. However, clinicians may experience reluctance to make changes to medication regimens, despite health-related risks, as pharmacological treatment for schizophrenia is often effective at treating psychotic symptoms [40], as well as reducing adverse outcomes such as relapse and hospitalisation [41].

A high proportion of participants across all professional groups selected substance abuse as a risk factor for CVD (overall $81 \%$ of the whole sample). Studies from the general population have shown recreational drugs such as methamphetamine and cocaine can provoke a multifactorial dysfunction of the cardiovascular system $[42,43]$. Prevalence of substance abuse is high in people with schizophrenia [44], whereby between 40 and $50 \%$ of people with schizophrenia may have a comorbid substance use disorder (SUD) [45]. This rate is about three times as high as that of the general population [46]. SUDs are associated with poor treatment adherence and response, increase symptoms and the risk of relapse [46], and are associated with poorer physical health outcomes [47]. Substance abuse is not cited as a CVD risk factor in NICE guidance on CVD risk assessment and prevention [31, 32], although NICE does recommend monitoring the physical health of adults and young people with psychosis and comorbid substance misuse [48]. It was therefore reasonable for participants to identify substance use as a risk factor for CVD. A 2019 Lancet Psychiatry Commission has highlighted that people 
with SMI and SUD are at an increased risk of physical multimorbidity and addressing substance misuse within mental health services should be a high priority [49]. However, access to secondary health care for people with mental illness may be limited due to issues such as stigma and fragmentation of care [49]. Subsequently, people with mental illness and comorbid physical health problems likely receive an inferior standard of health care compared with the general population with the same physical health problems [49]. There is therefore a need for investment in integration of physical and mental health care.

Sleep problems have been linked to CVD in the general population $[29,50,51]$. However, they have not been included as such in NICE guidelines. Sleep problems are highly prevalent in people with schizophrenia $[16,52]$ but the link between sleep problems and CVD in schizophrenia requires more research. It is therefore not surprising that less than half of participants endorsed sleep as a CVD risk factor. If further research establishes sleep problems as a risk factor for CVD in schizophrenia, the assessment of sleep outcomes such as sleep quality and sleep duration should become part of routine training for NHS staff that support people with schizophrenia.

When examining whose responsibility participants felt it was to monitor the physical health of people with schizophrenia, there were high levels (over 90\%) seen on half the given options and there was no difference in responses between groups. This raises a risk of "diffusion of responsibility", in that the presence of other healthcare professionals providing support may make some feel less personally responsible for monitoring physical health [53]. Healthcare professionals in secondary care may believe the responsibility lies with healthcare professionals in primary care and vice visa.

Comparisons between groups showed significant differences in which healthcare professionals have delivered interventions to improve sedentary behaviour in people with schizophrenia, with nurses being the group with the highest proportion. This suggests that some physical health interventions are being incorporated into healthcare professionals' patient consultations but perhaps in an informal format. There was poor awareness of either of the government recommended interventions, MECC and VBA on smoking. While both MECC and VBA on smoking are designed to be used during any patient interaction, it appears they are not being implemented. Further, this survey may have over-estimated awareness of MECC and VBA on smoking as participants may have responded 'yes' to all nominated interventions without actually having heard of them, as suggested by the finding that 33 participants were aware of the non-existent VBA on sedentary behaviour.

Some limitations should be considered in the interpretation of the findings of this study. Participants were asked whether they had ever delivered any effective interventions to improve sedentary behaviour in people with schizophrenia and signposting and referrals were provided as examples. First, the term 'effective' was not defined and it is therefore possible participants might have delivered an intervention, with no way of knowing whether it was effective. Second, it was not surprising that signposting and referrals were the two most common interventions cited given these were examples provided. This could therefore have been construed as suggestive. Nonetheless, participants did cite other interventions independently such as encouragement and verbal advice.

A strength of this study was the large number of participants across a range of clinical staff. The anonymity of the survey also enabled participants to be honest in their responses.

\section{Conclusions}

Healthcare professionals' awareness of many established risk factors for CVD is high but, only moderate numbers identified sleep problems or antipsychotic/antidepressant use as risk factors, with higher numbers identifying substance abuse despite this not appearing as a CVD risk factor in NICE guidance [31, 32]. Previous research found that the physical health of people with schizophrenia and related psychotic illnesses was not well monitored or investigated [54]. While we did not ask specifically about whether participants monitored patients' physical health and risk factors for CVD, the lack of awareness about some risk factors could mean that monitoring of physical health is sub-optimal. Coupled with the lack of clarity about responsibility for physical health care, this raises the possibility that some risk factors may not be monitored and that an overall picture of a patient's CVD risk may not be considered. Poor physical health in people with SMI decreases well-being [39], reduces adherence to prescribed medication [37] and hinders recovery from mental health symptoms [38]. This adds to the social and economic burden of their mental illness $[55,56]$. We support the findings from the 2019 Lancet Psychiatry Commission that integrated care models are needed, with clear lines of accountability and responsibility, and good communication between primary and secondary care services [49].

\section{Supplementary information}

Supplementary information accompanies this paper at https://doi.org/10. 1186/s12913-020-05654-z.

\section{Additional file 1.}

\section{Abbreviations}

CBT: Cognitive behavioural therapy; CRN: Clinical Research Network; CSO: Clinical studies officer; CVD: Cardiovascular disease; GMMH: Greater Manchester Mental Health NHS Foundation Trust; GP: General practitioner; 
MECC: Making Every Contact Count; NICE: National Institute for Health and Care Excellence; NIHR: National Institute for Health Research; PCFT: Pennine Care NHS Foundation Trust; SMI: Severe mental illness; SUD: Substance use disorder; UK: United Kingdom; VBA: Very Brief Advice

\section{Acknowledgements}

$A B$ is funded by a Medical Research Council (MRC) Doctoral Training Scholarship.

We would like to thank the NIHR Clinical Research Network (CRN) clinical studies officers (CSOS) for their support in recruitment by helping to identify and recruit suitable participants.

\section{Authors' contributions}

$A B$ and $A Y$ were responsible for the study concept and design. $A B$ was responsible for the data collection and statistical analysis. $A B, R D$ and $A Y$ were responsible for drafting and critical revision of the manuscript. $A B, R D$ and $A Y$ have approved the submitted version and modified version.

\section{Funding}

This piece of research was funded by the Medical Research Council and University of Manchester as part of A. Berry's MRC Doctoral Training Scholarship.

\section{Availability of data and materials}

The dataset used and/or analysed during the current study are available from the corresponding author on reasonable request.

\section{Ethics approval and consent to participate}

The study received ethical approval from the North West Research Ethics Committee (17/NW/0368). It was also adopted by the National Institute for Health Research (NIHR) Clinical Research Network (CRN) Portfolio (34859). Implied consent was obtained by completion of the survey. All participants were fully informed upon receiving a Participant Information Sheet. No identifiable information was collected.

\section{Consent for publication}

Not applicable.

\section{Competing interests}

The authors declare that the research was conducted in the absence of any commercial or financial relationships that could be construed as a potential conflict of interest.

\section{Author details}

${ }^{1}$ Division of Psychology \& Mental Health, School of Health Sciences, Faculty of Biology, Medicine and Health, University of Manchester, Manchester Academic Health Sciences Centre (MAHSC), Manchester, UK. ${ }^{2}$ Greater Manchester Mental Health NHS Foundation Trust, Manchester, UK. ${ }^{3}$ Centre for Youth Mental Health, The University of Melbourne, Parkville, Victoria, Australia.

Received: 15 September 2019 Accepted: 13 August 2020

Published online: 20 August 2020

\section{References}

1. Saha S, Chant D, McGrath J. A systematic review of mortality in schizophrenia: is the differential mortality gap worsening over time? Arch Gen Psychiatry. 2007;64(10):1123-31.

2. Walker ER, McGee RE, Druss BG. Mortality in mental disorders and global disease burden implications: a systematic review and meta-analysis. JAMA Psychiatry. 2015;72(4):334-41.

3. Nordentoft M, Wahlbeck K, Hällgren J, Westman J, Ösby U, Alinaghizadeh H, et al. Excess mortality, causes of death and life expectancy in 270,770 patients with recent onset of mental disorders in Denmark, Finland and Sweden. PLOS ONE. 2013;8(1):e55176.

4. Hennekens $\mathrm{CH}$, Hennekens AR, Hollar D, Casey DE. Schizophrenia and increased risks of cardiovascular disease. Am Heart J. 2005;150(6):1115-21.

5. Brown S. Excess mortality of schizophrenia. A meta-analysis. Br J Psychiatry. 1997;171:502-8.
6. Westman J, Eriksson SV, Gissler M, Hallgren J, Prieto ML, Bobo WV, et al. Increased cardiovascular mortality in people with schizophrenia: a 24-year national register study. Epidemiol Psychiatr Sci. 2017;27(5):1-9.

7. Correll CU, Solmi M, Veronese N, Bortolato B, Rosson S, Santonastaso P, et al. Prevalence, incidence and mortality from cardiovascular disease in patients with pooled and specific severe mental illness: a large-scale metaanalysis of 3,211,768 patients and 113,383,368 controls. World Psychiatry. 2017;16(2):163-80

8. Annamalai A, Tek C. An overview of diabetes management in schizophrenia patients: office based strategies for primary care practitioners and endocrinologists. Int J Endocrinol. 2015;969182.

9. Fox CS, Coady S, Sorlie PD, D'Agostino RB, Pencina MJ, Vasan RS, et al. Increasing cardiovascular disease burden due to diabetes mellitus. Circulation. 2007;115(12):1544.

10. Mitchell AJ, Vancampfort D, Sweers K, van Winkel R, Yu W, De Hert M. Prevalence of metabolic syndrome and metabolic abnormalities in schizophrenia and related disorders - a systematic review and metaanalysis. Schizophr Bull. 2013;39(2):306-18.

11. Pillinger T, McCutcheon RA, Vano L, Mizuno Y, Arumuham A, Hindley G, et al. Comparative effects of 18 antipsychotics on metabolic function in patients with schizophrenia, predictors of metabolic dysregulation, and association with psychopathology: a systematic review and network metaanalysis. Lancet Psychiat. 2020;7(1):64-77.

12. International Diabetes Federation (IDF). The IDF consensus worldwide definition of the metabolic syndrome. Available from: https://www.idf.org/ component/attachments/attachments.html?id=705\&task=download 2006. Last accessed: $20^{\text {th }}$ July 2020.

13. Chen $\mathrm{Y}-\mathrm{L}$, Pan $\mathrm{C}-\mathrm{H}$, Chang $\mathrm{C}-\mathrm{K}$, Chen $\mathrm{P}-\mathrm{H}$, Chang H-M, Tai M-H, et al. Physical illnesses before diagnosed as schizophrenia: a nationwide casecontrol study. Schizophr Bull. 2020;46(4):785-94.

14. Kelly DL, McMahon HJ, Wehring HJ, Liu F, Mackowick KM, Boggs DL, et al. Cigarette smoking and mortality risk in people with schizophrenia. Schizophr Bull. 2011;37(4):832-8.

15. Vancampfort D, Probst M, Knapen J, Carraro A, De Hert M. Associations between sedentary behaviour and metabolic parameters in patients with schizophrenia. Psychiatry Res. 2012;200(2):73-8.

16. Keshavan MS, Tandon R. Sleep abnormalities in schizophrenia: pathophysiological significance. Psychol Med. 1993;23(4):831-5.

17. Wulff K, Dijk D-J, Middleton B, Foster RG, Joyce EM. Sleep and circadian rhythm disruption in schizophrenia. Brit J Psychiat. 2012;200(4):308-16.

18. Smith DJ, Langan J, McLean G, Guthrie B, Mercer SW. Schizophrenia is associated with excess multiple physical-health comorbidities but low levels of recorded cardiovascular disease in primary care: cross-sectional study. BMJ Open. 2013;17(3):e002808.

19. Crump C, Winkleby MA, Sundquist K, Sundquist J. Comorbidities and mortality in persons with schizophrenia: a Swedish national cohort study. Am J Psychiat. 2013;170(3):324-33.

20. Mitchell AJ, Lord O, Malone D. Differences in the prescribing of medication for physical disorders in individuals with $\mathrm{v}$. without mental illness: metaanalysis. Brit J Psychiat. 2012;201(6):435-43.

21. The Schizophrenia Commission. The Abandoned Illness: A Report from the Schizophrenia Commission. London: Rethink Mental Illness; 2012.

22. Mackell JA, Harrison DJ, McDonnell DD. Relationship between preventative physical health care and mental health in individuals with schizophrenia: a survey of caregivers. Ment Health Serv Res. 2005;7:225-8.

23. Mitchell AJ, Delaffon V, Vancampfort D, Correll CU, De Hert M. Guideline concordant monitoring of metabolic risk in people treated with antipsychotic medication: systematic review and meta-analysis of screening practices. Psychol Med. 2012:42(1):125-47.

24. Naylor C, Das P, Ross S, Honeyman M, Thompson J, Gilbert H. Bringing together physical and mental health: a new frontier for integrated care. London: The King's Fund; 2016.

25. NHS England. Improving physical healthcare for people living with severe mental illness (SMI) in primary care. Guidance for CCGs. Available from: https:// www.england.nhs.uk/wp-content/uploads/2018/02/improving-physical-healthcare-for-smi-in-primary-care.pdf 2018. Last accessed: $20^{\text {th }}$ July 2020.

26. Hardy S. Mental health and wellbeing survey: a snapshot of practice nurses' views regarding responsibility and training. Available from: https://pdfs. semanticscholar.org/bdcd/cbb56c3ab805363bf5a996d39dab8d1f23bd.pdf?_ ga $=2.140834939 .89378407 .1585842318-1149433861.1585842318$ 2014. Last accessed: $20^{\text {th }}$ July 2020 
27. Jones S, Howard L, Thornicroft G. 'Diagnostic overshadowing': worse physical health care for people with mental illness. Acta Psychiatr Scand. 2008;118(3):169-71.

28. World Health Organization. The ICD-10 Classification of Mental and Behavioural Disorders. Diagnostic Criteria for Research. Geneva: World Health Organization; 1993.

29. Cappuccio FP, Cooper D, D'Elia L, Strazzullo P, Miller MA. Sleep duration predicts cardiovascular outcomes: a systematic review and meta-analysis of prospective studies. Eur Heart J. 2011;32(12):1484-92.

30. Cai $Y$, Hansell AL, Blangiardo M, Burton PR, BioShaRe, de Hoogh K, et al. Long-term exposure to road traffic noise, ambient air pollution, and cardiovascular risk factors in the HUNT and lifelines cohorts. Eur Heart J. 2017;38(29):2290-6.

31. National Institute for Health and Care Excellence. NICEimpact Cardiovascular disease prevention. Available from: https://www.nice.org uk/Media/Default/About/what-we-do/Into-practice/measuring-uptake/ nice-impact-cardiovascular-disease-prevention.pdf 2018. Last accessed: $20^{\text {th }}$ July 2020.

32. National Institute for Health and Care Excellence. Cardiovascular disease: risk assessment and reduction, including lipid modification. Available from: https://www.nice.org.uk/guidance/cg181/resources/cardiovascular-diseaserisk-assessment-and-reduction-including-lipid-modification-pdf-3510980766 0997 2014; updated 2016. Last accessed: 20 ${ }^{\text {th }}$ July 2020.

33. Hippisley-Cox J, Coupland C, Brindle P. Development and validation of QRIS K3 risk prediction algorithms to estimate future risk of cardiovascular disease: prospective cohort study. BMJ. 2017;357:j2099.

34. Osborn DP, Hardoon S, Omar RZ, Holt RIG, King M, Larsen J, et al. The PRIM ROSE cardiovascular risk prediction models for people with severe mental illness: results from the PRIMROSE research Programme: PRedlction and management of cardiovascular risk in peOple with SEvere mental illnesses. JAMA Psychiatry. 2015;72(2):143-51.

35. Public Health England. Making Every Contact Count (MECC): practical resources. Available from: https://www.gov.uk/government/publications/ making-every-contact-count-mecc-practical-resources 2016. Last accessed: $20^{\text {th }}$ July 2020

36. National Institute for Health and Care Excellence. Stop smoking interventions and services. Available from: https://www.nice.org.uk/ guidance/ng92/chapter/recommendations\#very-brief-advice 2018. Last accessed: $20^{\text {th }}$ July 2020 .

37. Wade $M$, Tai $S$, Awenat $Y$, Haddock G. A systematic review of service-user reasons for adherence and nonadherence to neuroleptic medication in psychosis. Clin Psychol Rev. 2017;51:75-95.

38. DiBonaventura M, Gabriel S, Dupclay L, Gupta S, Kim E. A patient perspective of the impact of medication side effects on adherence: results of a cross-sectional nationwide survey of patients with schizophrenia. BMC Psychiatry. 2012;12(1):20.

39. Hayhurst KP, Drake RJ, Massie JA, Dunn G, Barnes TR, Jones PB, et al. Improved quality of life over one year is associated with improved adherence in patients with schizophrenia. Eur Psychiatry. 2014;29(3):191-6.

40. McCutcheon RA, Pillinger T, Mizuno Y, Montgomery A, Pandian H, Vano L, et al. The efficacy and heterogeneity of antipsychotic response in schizophrenia: a meta-analysis. Mol Psychiatry. 2019. https://doi.org/10.1038/ s41380-019-0502-5.

41. Leucht S, Tardy M, Komossa K, Heres S, Kissling W, Davis JM. Maintenance treatment with antipsychotic drugs for schizophrenia. Cochrane Database Syst Rev. 2012;(5):Cd008016. https://doi.org/10.1002/14651858.CD008016. pub2.

42. Kevil CG, Goeders NE, Woolard MD, Bhuiyan MS, Dominic P, Kolluru GK, et al. Methamphetamine use and cardiovascular disease. Arterioscler Thromb Vasc Biol. 2019;39(9):1739-46.

43. Kim ST, Park T. Acute and chronic effects of cocaine on cardiovascular health. Int J Mol Sci. 2019;20(3):584

44. Hartz SM, Pato CN, Medeiros H, Cavazos-Rehg P, Sobell JL, Knowles JA, et al. Comorbidity of severe psychotic disorders with measures of substance use. JAMA Psychiatry. 2014;71(3):248-54.

45. Hunt GE, Large MM, Cleary M, Lai HMX, Saunders JB. Prevalence of comorbid substance use in schizophrenia spectrum disorders in community and clinical settings, 1990-2017: systematic review and meta-analysis. Drug Alcohol Depend. 2018;191:234-58.

46. Dixon L. Dual diagnosis of substance abuse in schizophrenia: prevalence and impact on outcomes. Schizophr Res. 1999;35:S93-S100.
47. Hjorthøj C, Østergaard ML, Benros ME, Toftdahl NG, Erlangsen A, Andersen $\mathrm{T}$, et al. Association between alcohol and substance use disorders and allcause and cause-specific mortality in schizophrenia, bipolar disorder, and unipolar depression: a nationwide, prospective, register-based study. Lancet Psychiat. 2015;2(9):801-8.

48. National Institute for Health and Care Excellence. Coexisting severe mental illness (psychosis) and substance misuse: assessment and management in healthcare settings. Available from: https://www.nice.org.uk/guidance/cg12 0/resources/coexisting-severe-mental-illness-psychosis-and-substancemisuse-assessment-and-management-in-healthcare-settings-pdf-351094431 84325 2011. Last accessed: $20^{\text {th }}$ July 2020.

49. Firth J, Siddiqi N, Koyanagi A, Siskind D, Rosenbaum S, Galletly C, et al. The lancet psychiatry commission: a blueprint for protecting physical health in people with mental illness. Lancet Psychiat. 2019;6(8):675-712.

50. Kwok CS, Kontopantelis E, Kuligowski G, Gray M, Muhyaldeen A, Gale CP, et al. Self-reported sleep duration and quality and cardiovascular disease and mortality: A dose-response meta-analysis. J Am Heart Assoc. 2018;7(15): e008552.

51. Nagai M, Hoshide S, Kario K. Sleep duration as a risk factor for cardiovascular disease- a review of the recent literature. Curr Cardiol Rev. 2010;6(1):54-61.

52. Tandon R, Shipley JE, Taylor S, Greden JF, Eiser A, DeQuardo J, et al. Electroencephalographic sleep abnormalities in schizophrenia. Relationship to positive/negative symptoms and prior neuroleptic treatment. Arch Gen Psychiat. 1992;49(3):185-94.

53. Dubov A, Fraenkel L, Seng E. The importance of fostering ownership during medical training. Am J Bioeth. 2016;16(9):3-12.

54. Carney R, Bradshaw T, Yung AR. Monitoring of physical health in services for young people at ultra-high risk of psychosis. Early Interv Psychiatry. 2018; 12(2):153-9.

55. Manu P, Khan S, Radhakrishnan R, Russ MJ, Kane JM, Correll CU. Body mass index identified as an independent predictor of psychiatric readmission. J Clin Psychiatry. 2014;75(6):e573-7.

56. Alvarez-Jiménez M, González-Blanch C, Crespo-Facorro B, Hetrick S, Rodríguez-Sánchez JM, Pérez-Iglesias R, et al. Antipsychotic-induced weight gain in chronic and first-episode psychotic disorders: a systematic critical reappraisal. CNS Drugs. 2008;22(7):547-62

\section{Publisher's Note}

Springer Nature remains neutral with regard to jurisdictional claims in published maps and institutional affiliations.

\section{Ready to submit your research? Choose BMC and benefit from:}

- fast, convenient online submission

- thorough peer review by experienced researchers in your field

- rapid publication on acceptance

- support for research data, including large and complex data types

- gold Open Access which fosters wider collaboration and increased citations

- maximum visibility for your research: over $100 \mathrm{M}$ website views per year

At $\mathrm{BMC}$, research is always in progress.

Learn more biomedcentral.com/submissions 